\title{
Guillaume Cuchet, Faire de l'histoire religieuse dans une société sortie de la religion
}

Paris, Publications de la Sorbonne, coll. «Itinéraires », 2013, 236 p.

Pierre Lassave

\section{OpenEdition}

Journals

Édition électronique

URL : http://journals.openedition.org/assr/25445

DOI : 10.4000 /assr.25445

ISSN : $1777-5825$

Éditeur

Éditions de l'EHESS

Édition imprimée

Date de publication : 30 décembre 2013

Pagination : 167

ISSN : 0335-5985

Référence électronique

Pierre Lassave, " Guillaume Cuchet, Faire de l'histoire religieuse dans une société sortie de la religion », Archives de sciences sociales des religions [En ligne], 164 | 2013, mis en ligne le 19 février 2014, consulté le 21 septembre 2020. URL : http://journals.openedition.org/assr/25445 ; DOI : https://doi.org/ $10.4000 /$ assr. 25445

Ce document a été généré automatiquement le 21 septembre 2020.

(c) Archives de sciences sociales des religions 


\section{Guillaume Cuchet, Faire de l'histoire religieuse dans une société sortie de la religion}

Paris, Publications de la Sorbonne, coll. « Itinéraires », 2013, 236 p.

\section{Pierre Lassave}

\section{RÉFÉRENCE}

Guillaume Cuchet, Faire de l'histoire religieuse dans une société sortie de la religion, Paris, Publications de la Sorbonne, coll. «Itinéraires », 2013, 236 p. 
1 Depuis les années 1980, tout historien universitaire qui se respecte est amené tôt ou tard à se livrer à l'exercice périlleux de son « ego-histoire ». Une manière, comme le précisait Pierre Nora, initiateur de ce nouveau genre d'essai, "d'expliciter en historien le lien entre l'histoire qu'on a faite et l'histoire qui vous a faite ». Cette entreprise réflexive a surtout été le fait d'auteurs ayant une belle carrière derrière eux, souvent sollicités par leurs pairs pour ouvrir leur atelier au public
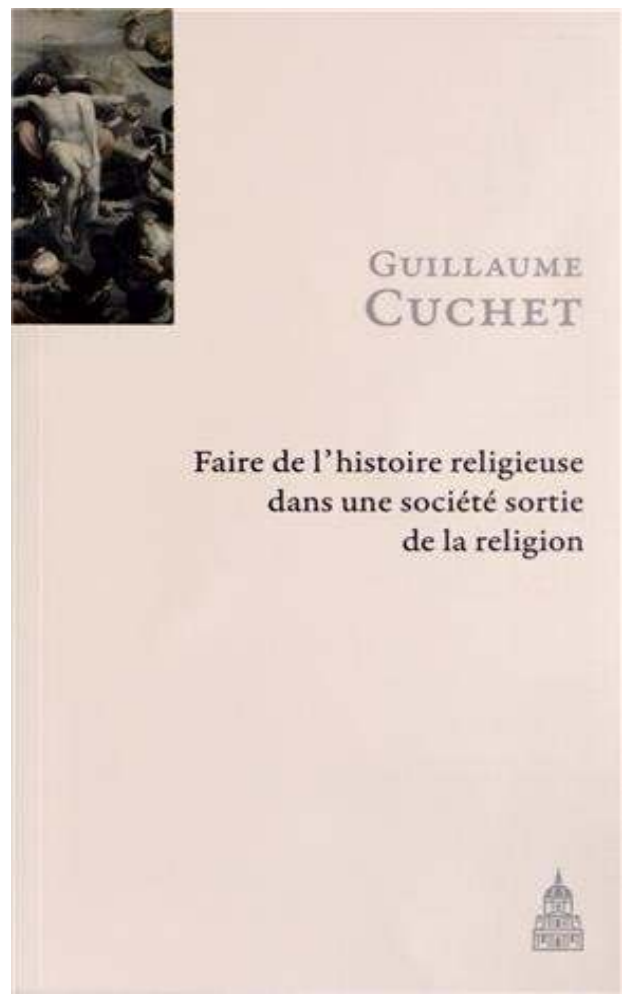
éclairé. Depuis quelques années, la soutenance des dossiers d'habilitation à diriger des recherches engage l'impétrant dans un type similaire de rétrospection intellectuelle. Grossit dès lors une masse de récits inédits de laquelle l'éditeur (Publications de la Sorbonne) tente depuis peu d'extraire les «Itinéraires " (nom de la collection) les plus parlants. Initiative qui devrait rajeunir l'ego-histoire tout en la limitant à des séquences de recherche plus proches du lancement que de l'achèvement.

2 Né en 1973, l'auteur de cet itinéraire appartient à la génération qui vient après celle du renouveau universitaire de l'histoire religieuse au cours des Trente glorieuses et après celle des baby-boomers qui ont prolongé l'ouverture de leurs maîtres jusqu'à la fin du siècle. Ses enquêtes récemment publiées sur le spiritisme au XIX siècle et peu auparavant sur le Purgatoire font déjà référence. Ses nombreux articles révèlent aussi un spécialiste de l'histoire du catholicisme qui circule en fait à double sens entre le XIX et le temps présent pour comprendre et expliquer les ruptures de croyance religieuse en même temps que les représentations savantes censées en rendre compte. Le titre de son essai est parlant pour les initiés: "faire de l'histoire » est une expression historiographique marquée par les signatures prestigieuses de Lucien Febvre, de Michel de Certeau et de Jacques Le Goff ; « société sortie de la religion » évoque le célèbre essai de Marcel Gauchet sur le « désenchantement du monde ». L'ouvrage se divise en deux parties : d'abord les conditions et les composantes d'un itinéraire ; ensuite un recueil de quatre études centrées sur des figures historiennes marquantes qui ont jalonné la réflexion épistémologique de l'auteur (Fernand Boulard, Jean Delumeau, Claude Langlois, la controverse Albert de Broglie/Dom Guéranger).

Le récit n'a donc rien d'un parcours de recherche retracé de façon linéaire, mais se justifie plutôt par les questions qu'il pose à une spécialité universitaire, l'histoire religieuse, en prise au déclin associé de son objet, le catholicisme, et de ses chercheurs. Après les grandes études sur la peur, le péché, la mort ou le paradis qui ont fait les riches œuvres de « l'histoire des mentalités » dans les années 1960-1970, puis celles, à la génération suivante, sur les moments de crise (modernisme, rupture conciliaire, éclatement), la production savante semble s'essouffler au moment même où pourtant la 
question religieuse se fait plus présente dans l'espace public. Comment ce jeune normalien d'éducation catholique s'est-il alors lancé dans la carrière ? Discret, l'auteur évoque à peine une sensibilité précoce pour les expériences de foi vécue plutôt que quelque intérêt idéologique précis. Sa curiosité intellectuelle est en même temps attirée par l'effondrement brutal des pratiques et des valeurs catholiques dans les années où l'auteur lui-même arrive au monde. Après l'agrégation, il en fait son objet en se confrontant directement d'abord au contenu même des élaborations spirituelles, tel le destin brisé du Purgatoire. Une manière de s'inscrire dans les pas des grands auteurs qui ont défriché le terrain (Le Goff, Ariès, Vovelle, Chiffoleau). Le Purgatoire au XIx $x^{e}$ siècle laissait en effet une place vacante à l'historien des mentalités. L'auteur la saisit à de multiples échelles, des angoisses intérieures qui sourdent des archives aux constructions dogmatiques qui conjurent avec habileté la montée du spiritisme. La concomitance des temps s'impose à son regard : tendances lourdes à la sécularisation et phases de freinage du mouvement, telles les tentatives différenciées de renouvellement catholique dans les années 1850, 1930 et 1960. La thèse publiée sur le Purgatoire se prolonge par l'étude du mouvement spirite dans les années 1848-1875, de sa naissance à New York à son procès à Paris, qui donnera lieu à un second ouvrage de référence. L'attention soudaine à la vie des morts qui a réuni au milieu du XIX ${ }^{e}$ siècle l'intérêt laïc pour les phénomènes paranormaux, les croyances populaires aux revenants et le loisir mondain des tables tournantes n'a pas survécu au réquisitoire des institutions ecclésiales et académiques. Plus donc que de mentalité, c'est bien de dynamique sociale des croyances que l'historien traite et poursuit dans ses retranchements. Retranchements hérétiques hier, catholiques aujourd'hui. Variations temporelles des valeurs qui exigent de l'historien qu'il se rapproche du sociologue pour mieux les comprendre, mais aussi qu'il mesure les capacités de son propre outillage disciplinaire à en rendre raison. D'où l'impératif historiographique qui accompagne ce parcours et justifie ici la reprise de quatre études autour d'historiens engagés dans des expériences de connaissance aussi originales que révélatrices de leurs propres limites.

Exemplaire à cet égard est le cas du chanoine Fernand Boulard (1898-1977), prêtre diocésain et sociographe du reflux des pratiques cultuelles qui a su rassembler des données statistiques et documentaires inédites sur la période allant de l'après-guerre jusqu'aux ruptures des années 1960. Cas pathétique également puisque la différenciation spatiale du grand transfert de «la religion par cœur à la religion du cœur » (Yves Lambert) et ses relativisations historiques (la « fille â̂née de l'Église » n'a jamais été vraiment et uniformément fidèle) ont permis au chanoine sociologue de différer sa prise de conscience qu'un monde se dérobait sous ses pas et invalidait l'imposant appareil de mesure qu'il avait si patiemment construit. Autre exemple plus heureux de limite relative, le cas de Jean Delumeau, dont la grande œuvre sur la "pastorale de la peur » du XIII ${ }^{\mathrm{e}}$ au XVIII ${ }^{\mathrm{e}}$ mérite prolongements et nuances. L'attention portée par l'historien au surcroît de culpabilité comme médication héroïque dans les siècles de menaces pour l'Église semble n'avoir pas vu ses prolongements ni ses inflexions au XIX ${ }^{e}$ siècle lorsque le lion en chaire se faisait agneau au confessionnal, lorsque le Dieu terrible augustinien cohabitait avec le Dieu d'amour de saintes visionnaires. Cuchet associe l'intérêt pour l'histoire du péché dans les années marquées par Vatican II au rejet de la répression arbitraire qui a hanté toute une génération d'historiens éduqués sous la férule des pères. Il revient à Claude Langlois, de la génération suivante, d'approcher, avec Thérèse de Lisieux, au plus près de ces élans mystiques qui ont retrouvé le Dieu d'amour dans un $\mathrm{xIX}^{\mathrm{e}}$ siècle particulièrement 
tourmenté. C'est plus l'écriture comme expérience spirituelle rendue aux limites du dicible que le phénomène proprement religieux que l'historien poursuit de son exégèse pointilliste. Cuchet semble fasciné par «l'entreprise déconcertante» de Langlois; il retrouve sans doute dans cette tentative originale de poétique de l'écriture mystique de quoi satisfaire intellectuellement son goût profond pour la foi vécue. Comme pour faire contraste avec cette histoire du sentiment religieux rendue à ses extrémités littéraires et expérimentales, l'auteur revient pour finir au débat qui, au XIX siècle, contribua de fait à préciser les contours de l'histoire naturelle du christianisme: la longue polémique qui opposa le libéral Albert de Broglie, auteur de six volumes éclairants sur L'Église et l'Empire romain au iv $v^{e}$ siècle (1856-1866), à l'intransigeant Dom Guéranger. Une situation (tensions et conciliations entre science et foi sous le Second Empire); deux protagonistes (une élite libérale ouverte au monde, un clergé replié sur sa tradition); des enseignements (le mythe de la chrétienté au Moyen Âge, la logique politique des mystères, la leçon inclusive de l'Église primitive qui a su absorber et transcender le paganisme romain).

Autant d'études qui, au-delà de leur exemplarité de cas, attestent d'une grande maîtrise des sources et surtout d'une agilité intellectuelle certaine à dénouer les liens de continuité, à déceler les failles et les ruptures entre époques voisines, à passer aussi les frontières disciplinaires, notamment entre histoire, sociologie, épistémologie et anthropologie. Au terme de ce récit lesté d'études factuelles, le lecteur se dit que la relève de la "nouvelle histoire » de l'après-guerre pourrait être assurée si ce type de trajet prometteur venait à se multiplier. On peut parfois regretter que l'information soit quelque peu allusive (on aurait aimé en savoir plus sur ce " poème dans le poème " thérésien révélé par Langlois) ou insuffisante (par exemple, sur la naissance européenne des sciences positives des religions au moment du débat sur le « naturalisme historique »). Mais il reste surtout le plaisir d'avoir rencontré une belle séquence d'ego-histoire en train de se faire et à l'expression aussi enlevée que sensible. 